\title{
Los bienes públicos y el derecho de propiedad
}

\author{
Jacqueline Morand-Deviller \\ Profesora emérita en la Universidad Panthéon-Sorbonne \\ ja.morand@hotmail.fr
}

Recibido: 12 de septiembre de 2012

Aceptado: 24 de mayo de 2013

\begin{abstract}
Resumen
Las reflexiones realizadas sobre los bienes públicos experimentan en la actualidad un nuevo auge debido, principalmente, a la mundialización del concepto. Ciertamente, el aumento de las preocupaciones medioambientales resalta la importancia de una nueva categoría de bienes públicos, que todavía no ha sido abordada por los juristas: los bienes públicos mundiales, noción anglosajona que proviene de la economía y engloba a los bienes de valor universal, cuya gestión debe responder a objetivos de solidaridad.

En este contexto, debe señalarse que uno de los principales elementos del debate acerca de los bienes públicos medioambientales es el análisis de las amenazas de sobreexplotación y degradación que les afecta.

Por ello y para abordar este fenómeno, el presente trabajo distingue dos categorías de bienes (los bienes demaniales y los bienes públicos mundiales y nacionales) y examina cómo se ejerce el derecho de propiedad sobre cada una de ellas, centrándose en los tres atributos del mismo: el abusus, el asits y el fructus.
\end{abstract}

Palabras clave Bienes públicos, bienes demaniales, bienes públicos mundiales, derecho de propiedad, abusus, usus y fructus

\section{Public goods and the Right to property}

\begin{abstract}
Reflections collected in public property are currently experiencing a renewed prominence, due mainly to the globalization of the concept. Certainly, the increasing of environmental concerns highlights the importance of a new category of public goods, which hasn't been addressed by the jurists yet: global public goods, AngloSaxon notion coming from the economy and that encompasses universal value goods, whose management must meet objectives of solidarity.

In this context, it should be noted that one of the main elements of debate about environmental public goods is the analysis of the threats of overexploitation and degradation that affects them.

Therefore, and to address this phenomenon, this paper identifies two caíegories of goods (financial assets and global and nalional public goods) and examines how to exercise the property law on each of them, focusing on its three attributes: the abusus, usus and fructus.
\end{abstract}

Key words

Public goods, financial assets, global public goods, property law, abusus, usus and fructus. 
La reflexión sobre los bienes públicos conoce actualmente un nuevo auge de intensidad particular debido a la mundialización del concepto. Mientras anteriormente el tema de los bienes públicos se abordaba únicamente desde la perspectiva de la demanialidad nacional, el aumento de la fuerza irresistible que experimentan las preocupaciones medioambientales realza la importancia de una nueva categoría de bienes públicos: los bienes públicos mundiales. De forma paralela, un venerable concepto recobra su vigor: el del patrimonio común, que resquebraja las categorías y las fronteras tradicionales.

Uno de los principales intereses del debate contemporáneo acerca de los bienes públicos radica en incitar a la reflexión sobre los riesgos de la comercialización que azota peligrosamente a los bienes de una determinada índole. Ya a inicios del siglo $\mathrm{XX}$, las grandes eminencias en derecho administrativo habían Ilamado la atención sobre la singularidad de los bienes de dominio público cuyo régimen tenía que distinguirse cuidadosamente del de los bienes privados, bienes comerciales libremente gestionados por sus propietarios. La misma reacción surge hoy en día con respecto a los bienes medioambientales, amenazados por la sobreexplotación y la degradación.

De origen sobre todo anglosajón, la noción de bienes públicos mundiales la estudian principalmente economistas y politólogos, y no tanto los juristas, cuya tarea se antoja delicada debido a que se les pide traducir conceptos -ciertamente interesantes, pero atados a la teoría- en normas con efectos de derecho, por lo que, para lograr esta trasposición, se ven obligados a adentrarse en un valor sagrado: el derecho de propiedad.

Existen varios movimientos de pensamiento que se entrecruzan e influyen en los conceptos tradicionales. De manera general, el derecho de propiedad, al igual que el resto de derechos individuales y públicos, sufre la influencia de un movimiento que tiende a destacar los deberes de los propietarios. La propiedad "obliga", declaran solemnemente varios textos, entre ellos la constitución alemana, amonestación que se dirige a los propietarios privados, pero de la que no se escapan tampoco los propietarios públicos. Además, se manifiesta una reacción contra los riesgos a los que se expone la protección de los bienes debido a la búsqueda de la valorización económica de las propiedades públicas. Una vez más, el peso de las preocupaciones medioambientales desempeña el papel de "revelador" y obliga a los juristas, con un contagio irresistible, a modificar las normas y los comportamientos. Actualmente somos testigos de una evolución aparentemente contradictoria entre el reconocimiento y la consolidación del derecho de propiedad en todos sus atributos puesto al servicio de una buena gestión de los bienes de dominio nacional y local, y la voluntad de restringir los atributos tradicionales de dicho derecho para garantizar la protección de los bienes públicos mundiales. Los juristas tendrán que reducir estas contradicciones y aplicar unas reglas adecuadas con objeto de garantizar un equilibrio justo.

Cabe aquí recordar la oposición dividida entre dos modos de concebir la propie12 dad que se manifestaba en el antiguo derecho y que guarda relación con el debate 
contemporáneo. En la Edad Media, la apropiación de los bienes privados se basaba en la idea de solidaridad. Una misma finca era objeto de varias "tomas de posesión", distribuidas según el uso y disfrute que se ejercía sobre el bien y las diversas utilidades que se le daba. El uso compartido del bien se realizaba respetando en todo momento los derechos del prójimo. Además, según el concepto cristiano antaño dominante, el poder que el hombre ejercía sobre el bien no era sino una delegación del poder divino, verdadero propietario de la tierra. El hombre solamente disponía de un uso y disfrute temporal del que tenía que ser merecedor en función de su capacidad para utilizar el bien y de servir a la cadena de generaciones con las que estaba en deuda: el concepto de desarrollo sostenible tiene un origen antiguo.

Todo va a cambiar con el redescubrimiento del derecho romano por parte de los grandes juristas italianos del siglo XII. Este “derecho erudito", intelectualmente riguroso y de gran utilidad para el acceso a la economía capitalista, predomina, algunos siglos más tarde, sobre costumbres consideradas "bárbaras". La propiedad se convierte en individual, marcada por la soberanía (el dominium), aislando al propietario unido a su bien, con respecto al que dispone de la mayor libertad. Propiedad material en oposición a propiedad de disfrute, apropiación individualista que pone fin a la idea de solidaridad, de racionalismo y de subjetividad de los derechos.

Cabe recordar esta disputa entre dos culturas del derecho de propiedad porque, en cierta manera, se está volviendo a manifestar hoy en día. Si bien la libre disposición de los bienes por parte de sus propietarios sigue siendo un principio, cada vez se ve más restringida y limitada por las servidumbres administrativas de interés común, siendo los requisitos en materia de urbanismo y medio ambiente los principales responsables de esta regulación de la propiedad territorial. Esta consolidación de las limitaciones de interés general que se impone a los bienes privados alcanza inevitablemente a los bienes públicos, objeto de nuestra reflexión.

En derecho francés, la "protección" de la propiedad de los bienes públicos, a semejanza de la que garantiza la propiedad privada, ha sido proclamada por el Consejo constitucional. No obstante, cabe preguntarse qué cubre la noción de propiedad y la de protección en derecho positivo. En derecho internacional, existen numerosos convenios que proclaman generosamente la comunidad de determinados patrimonios, si bien habría que medir la efectividad de tal encantamiento. En cualquiera de los casos, hay que aventurarse con un debate complejo sobre el carácter específico del derecho de propiedad tal y como se debe ejercer tanto con respecto a los bienes públicos nacionales como a los bienes públicos mundiales, y sobre las consecuencias que su singularidad aporta a su gestión. Existen diversas respuestas diferentes dependiendo de la categoría de los bienes.

Estas palabras libres, sin duda demasiado superficiales, serán el amistoso homenaje rendido a Jean-Louis Autin. Servidor de la causa universitaria en su máxima exigencia, gracias a él hemos podido participar en defensas de tesis cuyos recuerdos perduran vivos en nuestra memoria. Tesis defendidas por jóvenes y brillantes discípu- 
los, ahora ya colegas, que son el origen de este "cóctel" que gira en torno a un bien público y patrimonio común universitario: la independencia.

Se establecerá una distinción entre las dos categorías a las que se ha hecho alusión: los bienes demaniales del derecho francés, objeto de una larga preocupación doctrinal que, tras haber conocido un cierto aletargamiento, está en pleno auge actualmente, y los bienes denominados mundiales, todavía poco abordados por los juristas. Para reflexionar sobre el contenido del derecho de propiedad ejercido sobre una u otra categoría, se recurrirá a la distinción tradicional entre los tres atributos del derecho de propiedad: el abusus (I), el usits (II) y elfructus (III).

\section{EL ABUSUS}

El abusus es el atributo más poderoso del derecho de propiedad. ¿En qué medida se pueden fijar límites a la libre cesión de los bienes públicos por parte de su propietario? Y si admitimos que la naturaleza peculiar de dichos bienes exige una protección y un estatus determinados, ¿qué cubre exactamente el término “protección”?

\section{A) Los bienes públicos mundiales}

Esta noción anglosajona proviene de la economía y transita por la ciencia política. Los "global public goods" y los "global commons" han dado lugar a interminables y enfáticos debates de los que muy a menudo estaban excluidos los juristas. Debates que han enfrentado a diversas escuelas y de donde surgen definiciones a menudo oscuras, inventarios variables y tipologías inciertas. EI PNUD enumera una lista extensa, inconexa y variable de estos bienes, poco útil para los juristas, no más útil en todo caso que la definición aportada por los economistas: "bien no rival y no exclusivo".

Igual de inoperativas son las proclamaciones de los premios nobeles, como la del antiguo secretario general de la ONU, K. Arman, cuando calificaba a los bienes públicos mundiales de "una paz más sólida, una prosperidad mejor compartida, un medio ambiente salvado", o la del economista J. Stiglitz, que identificaba cinco bienes públicos globales: la estabilidad económica internacional, la seguridad internacional (estabilidad política), el medio ambiente internacional, la ayuda humanitaria internacional y el conocimiento. Sin duda, esta postura de orden ético y político resulta de gran interés para los juristas, dado que perfila las finalidades que tienen que dar a la utilización de los bienes. Lo mismo ocurre con la paz, si bien, al ser demasiado general, deben fijarse objetos de estudio más precisos e identificables.

No se trata aquí de valores en el sentido ético, sino de bienes, "elementos contemplados en el derecho", en el sentido material del término, distintos de los servicios y de los actos, y, más en concreto, de recursos naturales según los concibe el

14 derecho del medio ambiente. Hay que evitar varios escollos: el de una amalgama con 
el Bien común, concepto aristotélico filosófico y jurídico, demasiado vasto y alejado de la realidad material de estos bienes-recursos, y el de una recuperación por la ideología neoliberal de los economistas, que integra los bienes públicos en un enfoque neomaterialista fundado en un sistema de producción y de intercambios.

Lo que sí existe ya es un consenso sobre el hecho de que se trata de bienes de valor universal, diferentes de los bienes comerciales, de que su gestión deberá responder a un objetivo colectivista de solidaridad bajo el control de autoridades supranacionales y de que esta ficción jurídica será útil y fecunda para responder a las tensiones y amenazas de nuestra época, contribuyendo a la aparición de valores universalizables.

Uno puede preguntarse si la promoción de determinados bienes públicos mundiales hasta elevarlos al rango de patrimonio común de la humanidad los preservaría contra el abasus. La respuesta será del estilo "sí, pero...". Habiendo visto la luz incidentalmente gracias al embajador maltes Avid Prado en 1954, no muy bien acogida por el medio de los intemacionalistas tradicionales, la noción se aplica a los fondos marinos, al espacio extraatmosférico y a los cuerpos celestes. Dichos bienes, hasta el momento sin propietario, no tienen dueño porque la humanidad carece de personalidad jurídica en la que apoyarse y, a primera vista, parecen encajar bastante bien en el concepto romano de res communis, que excluye cualquier derecho de propiedad.

Pero la situación de dichos bienes es susceptible de evolucionar, haciéndoles perder esta condición y convirtiéndolos en apropiables. En efecto, podemos suponer que los rápidos adelantos del progreso de las técnicas harán que algunos de estos bienes sean explotables. La no apropiación cesará, se presentarán propietarios y la inembargable "humanidad" se disipará ante los Estados soberanos. Por tanto, estos bienes no son, por ahora, susceptibles de abusits, itsus y fructus, pero nada los protege en el futuro contra la codicia de los Estados. Evidentemente, podemos admitir que los compromisos sobre su estatus solamente intervienen en proporción a su explotabilidad, si bien la prudencia de las naciones pide ya a la comunidad internacional que reflexione sobre su futura explotabilidad y sobre los riesgos de apropiación por los únicos Estados con el poder suficiente para garantizar dicha explotación.

El Tratado Antartico de 1959 sigue siendo un modelo a este respecto. En contra de los proyectos de internacionalización que tienden a favorecer a la ley del más fuerte, fijó las reglas de no apropiación territorial por los Estados y de prohibición de las actividades militares. La prohibición atañe así mismo a la explotación de los recursos minerales, ricos pero poco explotables por el momento, autorizando exclusivamente las investigaciones con fines científicos. A pesar de las discordias y de las presiones, esta limitación se sigue respetando hoy en día. No habiendo previsto nada para el Ártico, cuyos recursos se pueden explotar con mayor facilidad, esta inmensa reserva de riqueza suscita conflictos de diversa naturaleza, que continuarán ampliándose inexorablemente y que amenazan seriamente a la biodiversidad. Esperemos que los proyectos de identificación de bienes mundiales medioambientales a preservar ocupen un lugar importante en las negociaciones en curso. 


\section{B) Los bienes públicos nacionales}

En teoría, estos bienes están protegidos contra los riesgos de exceso del abusus tanto por un principio aplicable sobre todo a los bienes medioambientales -el del patrimonio común de la nación-, como por la regla tradicional del patrimonio público: la inalienabilidad.

Desde su aparición hace un cuarto de siglo en Francia, la noción de patrimonio común de la nación ha sido objeto de una dispersión sin precedentes en el momento en el que se desarrolló la protección medioambiental: el territorio francés, el agua y, de forma general, "los espacios, recursos y medios naturales, los parajes y paisajes, la calidad del aire, las especies animales y vegetales, la diversidad y los equilibrios biológicos en los que participan" han pasado a formar parte del arca patrimonial, lo que resume, con una fórmula lapidaria, la Carta del medio ambiente de 2005 al afirmar que "el medio ambiente es el patrimonio común de los seres humanos".

A diferencia del patrimonio común de la humanidad, la mayor parte de los elementos del patrimonio nacional tienen un propietario; el concepto de "nación" o de "seres humanos" ennoblece a los bienes, pero no cambia en absoluto su condición. Podemos citar aquí el territorio (ley de 1983) o el agua (ley del 3 de enero de 1992), excluyendo de la apropiación únicamente el agua del mar y las aguas corrientes no demaniales. Los cursos de agua son de dominio público fluvial, mientras que las aguas de las fuentes, las aguas subterráneas y las aguas pluviales se pueden apropiar por el propietario de la finca en donde se ubican: al agua no le faltan propietarios. Si se trata de propietarios privados, su libertad en lo que respecta al abusus es total, mientras que si se trata de propietarios públicos, la cuestión se traslada hacia la eficacia de la protección por las reglas de la demanialidad.

Una de las características de la demanialidad pública es el principio de inalienabilidad de los bienes, es decir, la ausencia de abusus. No obstante, es de todos sabido que la inalienabilidad se presenta más bien bajo la forma de alienabilidad condicional y que depende de las elecciones que adopte el propietario público en materia de gestión. Cuando desea que un bien de dominio público pase al dominio privado para proceder a su alienación, la persona pública propietaria no tiene más obligación que la de respetar las reglas de desafectación y de desclasificación, que, por otra parte, se ven ahora suavizadas por el reciente Código general de la propiedad de las personas públicas (CGPPP), cuyo título insiste, a propósito, en la existencia de un verdadero derecho de propiedad que pone fin a los antiguos debates.

La inalienabilidad siempre ha sido un principio maleable. Basta con acordarse de las viejas prácticas del descompromiso que permitían a los Reyes de Francia, que gozaban del derecho de "arrepentimiento", blandir virtuosamente el principio citado con objeto de no devolver los créditos que habían obtenido pignorando los bienes públicos; recordemos la reventa a los burgueses enriquecidos de la Revolución de 161789 de los bienes nacionales de los que se había despojado al dominio real, así como 
al de la nobleza y del clero, bienes declarados inalienables, aunque bajo reserva de una autorización de la Nación "soberana" cuyos representantes apenas tuvieron dificultad en hacer votar la cesión, a menudo en beneficio propio, una transmisión "inviolable y sagrada” poco después amparada por el artículo 544 del código civil.

Aunque no se trata ahora de insistir en esta flexibilidad en la gestión de los bienes públicos y en la libertad de cesión concedida a sus propietarios en nombre de una buena gobernanza, sí conviene preguntarse sobre las consecuencias de la política de cesiones masivas adoptada por varios países fundadores de la Unión europea, entre ellos Francia, para intentar sacar a flote presupuestos muy endeudados.

Inaugurada en los años 90 con los bienes del Ministerio de la Defensa nacional, la incitación a la cesión por parte del Estado de una parte de su patrimonio inmobiliario se ha venido generalizando poco a poco, dando prueba una vez más de la gran libertad de la que gozan los propietarios públicos para ceder sus bienes.

También merece la pena detenerse en la noción de “protección” de los bienes públicos nacionales, adoptada por el Consejo constitucional en la célebre resolución "Privatizaciones" de junio de 1986. Cuando el Consejo afirma que se benefician, "de igual modo", de la misma protección que la que se confiere a la propiedad privada de los particulares conforme al artículo 17 de la Declaración de derechos de 1789, pretende proteger el valor comercial de los bienes de las empresas públicas que en su mayoría se estaban privatizando. Por tanto, se trata esencialmente de una protección económica y financiera: no ceder los bienes públicos a precios inferiores a su valor de mercado. Se recuerda la libertad de la que goza el gobierno para apreciar la oportunidad de las transmisiones del sector público al sector privado y el Consejo se abstiene de dar precisiones sobre la excepción relativa a los bienes de los "servicios públicos con carácter nacional”.

Con la aparición de los "bienes medioambientales", parece que la protección de los bienes públicos nacionales adquiere una nueva dimensión, limitando la maleabilidad de la inalienabilidad. El propio "núcleo duro" del dominio público destinado al uso del público se puede ver amenazado, por lo que sería recomendable prever para determinados bienes condiciones más rigurosas que las que existen actualmente en lo que respecta a la desafectación y reclasificación. Pensamos, por ejemplo, en los bienes del Conservatorio del litoral, en los parques naturales o en determinados bienes del dominio privado, como los bosques. Podemos imaginar, por ejemplo, que exista la obligación de obtener la conformidad de las comunidades (una noción que habrá que precisar) implicadas en las cesiones. Cabe recordar que la democracia participativa puesta al servicio de los bienes medioambientales "patrimonio común de los seres humanos" es una obligación de orden constitucional.

\section{USUS}

¿Soberanía o uso? Esta antigua polémica sobre el derecho de propiedad resurge hoy en día y hace que nos planteemos cuáles son los nuevos usuarios y las nue- 
vas modalidades de uso y disfrute de los bienes públicos mundiales y de los bienes mundiales.

\section{A) Los bienes públicos mundiales}

La publicación, en 1999, en una obra colectiva, del artículo de Garret Hardin " $L a$ tragedia de los bienes comunes", mostrando la correlación entre los "males mundiales" y las amenazas que pesan sobre los bienes públicos mundiales, contribuyó a promover la idea de un reconocimiento de la existencia de estos bienes, que se podría consagrar mediante el derecho. Sin embargo, dicha consagración todavía se encuentra en fase embrionaria.

Como ya se ha comentado, el concepto ha llamado la atención de economistas y politólogos principalmente, mientras que los juristas se han quedado al margen del debate. El Banco mundial, a semejanza del PNUD, elaboró una definición muy extensa: "productos, recursos, servicios, sistemas de reglas o regímenes políticos...", sin preocuparse de entrar en detalle en la cuestión de la propiedad, contentándose con invocar vagamente una patrimonialidad común.

El vínculo entre males mundiales e insuficiencia de los bienes públicos mundiales ocupa desde entonces una posición central en los debates. No obstante, se han producido avances y han surgido determinadas ideas y propuestas muy interesantes en un sector particularmente sensible: el del agua. Hay que evitar que la batalla por el oro azul adquiera los ásperos matices que caracterizan los conflictos económicos que rodean al oro negro y al oro amarillo. Desde el momento en el que hay una escasez de un recurso surgen rivalidades de consumo y, con ellas, el riesgo de que la gestión de la oferta predomine sobre la de la propia demanda, aunque sea prioritaria. Las mentalidades evolucionan y ahora consideramos que el agua se tiene que ver como una res communis omnium, algo ilimitado a disposición de todos por igual con una finalidad de utilidad colectiva. Dado que existe un riesgo de escasez y de penuria, ya no se puede considerar una res mdliiis, que pertenece a todos y a nadie en particular, dado que dicho concepto implica abundancia. Los símbolos del arenque de Grotius o del amor maternal de Víctor Hugo: "Cada uno tiene su parte y todos tienen el todo" ya no son válidas.

El derecho comparado muestra el desarrollo de los usos colectivos en la mayoría de los países, así como la disminución de las aguas privadas y de la libertad de uso de los ribereños. En la Agenda 21 se proclama el agua como "bien social y económico", la Directiva marco comunitaria del 23 de octubre de 2000 reconoce que el agua "no es un bien comercial como el resto, sino un patrimonio" y la asamblea general de la ONU adoptó, prácticamente por unanimidad, a propuesta de Bolivia, un proyecto de Resolución en donde se declara que "el derecho al agua potable salubre y limpia es un derecho fundamental esencial para el pleno ejercicio del derecho a la vida y de 18 todos los derechos del hombre", un discreto avance sin continuidad normativa. 
Los estudios sobre el crecimiento demográfico y sobre el aumento de las necesidades de consumo prevén que en el año 2025 cuarenta y ocho países, que representan más de un tercio de la población del planeta, se verán directamente afectados por la penuria de agua y parece que habrá que replantearse las reglas, a menudo bien pensadas y eficaces, que se aplican en determinados países, entre ellos Francia, desde una perspectiva global mundializada.

Hasta la fecha, en la práctica el uso del agua no se escapa ni de la apropiación ni de la comercialización. El reconocimiento de su carácter de bien público común no comercial obligará a inventar nuevos sistemas que se podrían inspirar en experiencias ya en práctica en determinados países. Se trataría, por una parte, de confiar el uso y la gestión del agua a entidades regionales de usuarios. El territorio de intervención sería distinto al de las circunscripciones administrativas tradicionales y se definiría en función de los intereses comunes de uso. Dichas entidades regularían la repartición de los usos y serían responsables a tal efecto. Y, por otra parte, los Estados y demás personas públicas, que no serían "propietarios" de un recurso considerado inapropiable, tendrían que desempeñar el papel de "guardianes": las funciones que hay que ejercer y los deberes que hay que cumplir sustituirían al título.

En la actualidad se están planteando este tipo de reformas, por ejemplo en Canadá. El concepto de Estado "guardián" se une al de Estado fiduciario, al de "public trust" y al de "parens patria", en una perspectiva de patrimonialidad común y de desarrollo sostenible. El desarrollo paralelo de una democracia participativa adquiere una envergadura supranacional, al igual que el procedimiento que, en caso de incumplimiento de la protección medioambiental, permite a los ciudadanos de los tres países -Canadá, EEUU y México- recurrir colectivamente a la Comisión medioambiental de ALEÑA, capacitada para pronunciar sanciones.

Podemos presentar otro ejemplo, entre muchos otros, de esta gestión directa por parte de entidades de habitantes, evocando un procedimiento adoptado en Madagascar en virtud de la ley del 30 de septiembre de 1996, el de la transferencia de la gestión de los recursos naturales (bosques, fauna y flora salvaje, entre otros) del dominio del Estado al de las comunidades de base, es decir, a los habitantes del territorio en donde se ubica el recurso en cuestión.

Dicha transferencia se produce a petición de los miembros de las comunidades y el Estado ha de dar su visto bueno a la misma, tras haber analizado las capacidades de gestión de la entidad de base. Una vez realizado lo que precede, la entidad y el Estado firman un contrato mediante el que se "confiere a la comunidad de base beneficiaría, durante un determinado periodo, la gestión del acceso, de la conservación, de la explotación y de la valorización de los recursos". La transferencia no implica la transmisión de propiedad de los recursos, sino una simple cesión de su uso y disfrute. No se prohibe la explotación con fines comerciales y el poder de la policía sigue en manos de las autoridades tradicionales. 


\section{B) Los bienes públicos nacionales}

En Francia, la doctrina y la jurisprudencia se mostraron durante mucho tiempo hostiles a la idea de que el dominio público pudiese ser objeto de propiedad. Al Consejo de Estado le costó bastante tiempo confirmar el tímido reconocimiento de la orden "Ville de París" de 1909 y la Audiencia Provincial hace uso de un eufemismo cuando dice que el Estado es "considerado propietario". Si buscamos la razón de esta resistencia, la encontramos en la idea de un uso común, equitativo y solidario, de los bienes "de uso de todos", el primer -y durante tiempo el único- criterio de reconocimiento.

El irresistible ascenso del segundo criterio, el del servicio público, su independencia en 1956 con respecto al primero y el desarrollo de los servicios públicos industriales y comerciales hicieron que las cosas tomasen otro cariz. Muy acogedor, debido a su imprecisión, el servicio público a la francesa permite el crecimiento exponencial del dominio público, el enriquecimiento de unas arcas que hay que rentabilizar, y un partenariado público-privado donde el principio de precariedad de las ocupaciones se aplica prácticamente solo a los ocupantes modestos.

Sin duda, en teoría, la propiedad demanial no era una propiedad como las demás, sin duda los comentarios de Maurice Hauriou sobre esta "propiedad administrativa" particular siguen siendo pertinentes, pero en realidad los modos de utilización, unilaterales o contractuales, del dominio público se acercaban cada vez más a los de los bienes privados, sin hacer a menudo diferencias entre los usuarios.

Esta evolución no es en absoluto condenable; los bienes públicos constituyen una riqueza económica que se tiene que gestionar eficazmente en aras del interés general, es decir, desde una lógica de mercado y de beneficio, y el CGPPP, de forma oportuna, puso término a las controversias anteriores consagrando oficialmente la existencia de un derecho de propiedad pleno y completo de las personas públicas sobre los bienes de su dominio. Por tanto, no es cuestión de volver hacia atrás ni de pretender que los bienes del dominio no estén sujetos a una lógica de mercado. Se trata de res in commercio, al menos en lo que respecta a la mayor parte de ellos, no a todos.

Vuelven a surgir aquí los retos medioambientales. Desde ahora, el principio de inalienabilidad hace que la demanialidad pública se erija como régimen protector, si bien podemos ir más allá y analizar el uso particular de determinados bienes del dominio, los bienes medioambientales, y prever que se restringirá la libertad concedida a los propietarios públicos no solamente en lo que respecta a su cesión, sino también a su uso.

Podríamos, por ejemplo, revalorizar el primer criterio de identificación, el de la adscripción al uso de todos, recordando la prioridad de este criterio y el principio se-

20 gún el cual el uso colectivo predomina sobre el uso privativo, cosa que tendemos a 
olvidar a veces. Siendo un derecho el acceso a los bienes públicos medioambientales, tal y como se ha dicho ya, la idea de un servicio público universal en el acceso a estos bienes permitiría, en caso necesario, anudar los vínculos entre los dos criterios.

También se podrían desarrollar experiencias de uso colectivo concediendo un derecho de uso y disfrute sobre los bienes demaniales medioambientales a las comunidades vinculadas a los habitantes que ocupan dichos bienes. Una propuesta de esta índole no tiene nada de incongruente, dado que el derecho francés ya la aplica desde hace siglos en el caso de los bienes comunales. Injustamente abandonado por la doctrina, este singular sistema merece, si cabe, más atención ahora que las preocupaciones medioambientales -de nuevo saltan a la palestra- abren un nuevo debate.

Este régimen, de origen consuetudinario, se remonta al Antiguo Régimen y se ha extendido mucho por Europa. Algunas tierras, en su mayoría pobres y en estado salvaje -tierras "vanas", bosques, pantanos, landas...-, se escapaban a la apropiación individual y su uso se cedía al conjunto de habitantes de la comuna, que tenían derechos adquiridos sobre ellas, como el pasto de animales, la cosecha de determinados productos, la recogida de madera... Bien es cierto que la comuna no poseía todavía un estatus propio y se percibía en aquel entonces como una comunidad privada de habitantes. A partir del siglo XVI, los señores quisieron apropiarse de algunos de estos bienes, lo que suscitó conflictos "sociales", principalmente en Inglaterra y en Francia, aunque aun así el sistema sobrevivió y fue consagrado en virtud de la ley del 10 de junio de 1793, según la cual dichos bienes “pertenecen, por su naturaleza, a la generalidad de los habitantes o miembros de las comunas o de las secciones de éstas". El consejo municipal es el que fija el modo de uso y disfrute común (principalmente en lo que respecta a los pastos) o individual (reparto de lotes). Estos bienes pertenecen al dominio privado y su régimen viene determinado en el código civil (art. 542). Esta propiedad colectiva en uso y disfrute abarca una superficie considerable del territorio francés: aproximadamente el 10\%.

Hasta ahora, a estos bienes no se les había prestado apenas atención debido a su pobreza y a la ausencia de interés económico, pero su situación está evolucionando por su riqueza ecológica. Preciosas reservas de biodiversidad, pueden despertar codicias de acondicionamiento y de explotación, así como la tentación de apropiación individual. Bajo la presión de los elegidos locales, chantres del desarrollo económico y rural, los legisladores podrían querer reformar el sistema, lo que ya se empezó a hacer con la ley del 3 de enero de 1967, que prevé un procedimiento de supresión de determinados "comunales" a cambio de una indemnización a tal efecto.

Si se generalizase dicha supresión, asistiríamos a una muerte brutal de un sistema venerable que tiene el inmenso mérito de responder a las preocupaciones actuales de protección de los bienes públicos medioambientales. Vanguardista, responde a la necesidad de reaccionar contra las amenazas que la apropiación individual supone para los bienes esenciales para la preservación de la biodiversidad y para la tímida progresión del concepto de propiedad colectiva en las reglas de derecho. 
La separación entre usus y abusas, en beneficio del primer atributo, se encuentra también en otros sistemas de derecho. Así, podemos citar el régimen inteligente del "National Trust", que ya cuenta con más de un siglo y que ha permitido salvaguardar a la vez el interés de los propietarios de los monumentos y jardines históricos, que ya no contaban con la capacidad de asumir el mantenimiento de los mismos por sí solos (conservan su uso y disfrute y se preserva su derecho de sucesión) y el interés general. La propiedad de los bienes se transfiere al National Trust, que garantiza su conservación y puesta en valor, si bien no goza de la libre disposición de los mismos, dado que son bienes a los que se aplica el concepto de inalienabilidad.

\section{FRUCTUS}

Herramienta multiuso, el derecho se siente normalmente cómodo con respecto a este atributo operacional del derecho de propiedad: su gestión. La cuestión que surge ahora es saber cuáles son los mejores gestores y los mejores métodos.

\section{A) Los bienes públicos mundiales}

Si admitimos que los bienes públicos mundiales no son susceptibles de apropiación individual, que su uso es común y su acceso igual para todos, parece que su gestión no se puede confiar únicamente a los Estados y que estos valores no comerciales no tienen por qué acatar la ley del mercado.

Hace varios años que surgió la cuestión de la necesidad de crear una Organización mundial del medio ambiente (OME). Dicho proyecto, que recibe el apoyo de las ONG y de diversos países, entre ellos Francia y Alemania, se encuentra, sin lugar a dudas, con resistencias que se basan en el argumento recurrente del freno al desarrollo y al libre mercado, si bien debería llegar a su término tarde o temprano. Esta nueva institución serviría para completar de manera útil la arquitectura internacional influyendo en la conducta de los organismos encargados de regular el desarrollo económico -la OMC y el FMI- e integrándose en las políticas adoptadas por la OMS y la OIT.

Organismo apolítico independiente, tendría por vocación regular la gestión de los recursos naturales a escala global, en una lógica distinta a la del mercado. Dispondría de un poder de iniciativa, sería un foro de negociación, se podría recurrir a él en materia de dumping medioambiental y contribuiría a la aplicación de los convenios internacionales.

También deberíamos presenciar el desarrollo de los Consejos mundiales especializados en la gestión de determinados recursos, si bien sería necesario que dispusiesen de una legitimidad incontestable. El Consejo mundial del agua constituye un claro ejemplo de la complejidad que entraña esta cuestión. Fundado en 1996, agrupa a un

22 número importante de organismos, tanto públicos como privados, cuenta con su 
sede en Marsella y organiza los Foros mundiales del agua cada tres años, habiéndose celebrado los dos últimos en México (2006) y en Estambul (2009). Se trata de encuentros y negociaciones de gran interés que dan lugar a generosas proclamaciones. A modo de ejemplo, el agua se declaró "bien público universal" y el Consejo se comprometió a apoyar el reconocimiento por parte de la ONU del derecho fundamental de acceso equitativo al agua. Sin embargo, se le puede reprochar su ausencia de independencia y su falta de legitimidad, ya que está dirigido por representantes de grandes empresas privadas de distribución del agua y los detractores más acervos no dudan en tildar al Consejo de "máquina para conquistar mercados", calificación excesiva sin duda alguna, y de crear estructuras y foros competidores.

Tratándose de modos de gestión de bienes públicos mundiales, solamente cabe una gestión integrada, debiendo abarcar el recurso de forma holística en su multifuncionalidad económica y ecológica. La integración tendrá que ser horizontal y constatamos avances en el refuerzo de la gestión transfronteriza. También ha de ser vertical, debiendo conducir a una cierta descentralización en el marco de las cuencas (véase la Declaración de Dublín de 1992).

Además, se debería encontrar un equilibrio entre el recurso a mecanismos puramente públicos y el llamamiento a un partenariado público-privado. El mantenimiento de los recursos naturales necesita a menudo de grandes inversiones, por lo que no se puede excluir la intervención de grandes empresas privadas y de sus conocimientos tecnológicos. Aun así, convendría que no predominasen las reglas de gestión ni las lógicas económicas puras.

Desde hace varios años se ha venido desarrollando un movimiento nacido de la imaginación fértil de los economistas que quieren conferir un valor económico a los recursos naturales cuando se ven amenazados por la escasez y el agotamiento de las reservas.

Estos estudios sobre la economía de los ecosistemas (véanse principalmente los del economista indio Pavan Sukhed) insisten sobre lo mucho que urge reaccionar ante el deterioro y el agotamiento creciente del capital natural y estiman que hay que dotar de un precio a la naturaleza para poder protegerla. El interés de estas demostraciones radica en que vinculan los tres pilares del desarrollo sostenible: el desarrollo económico, la equidad social y la protección del medio ambiente.

De hecho, el pillaje incontrolado de los recursos naturales se percibe a la vez como un ataque a la ecología, un ataque al desarrollo económico y un ataque a la equidad social, dado que el comportamiento de las multinacionales, depredadoras que se aprovechan libre y gratuitamente de los servicios ecosistémicos, lo que se conoce como el comportamiento del "ticket gratuito" o del "pasajero clandestino", priva a las comunidades autóctonas de los recursos que utilizan para su subsistencia. La preocupación por preservar la biodiversidad, los habitáis, los bosques y los factores de supervivencia para la humanidad, conduce a proponer la remuneración de las 
externalidades positivas. De forma más general, se plantea la cuestión de poner un precio a pagar por la utilización de la naturaleza, hasta ahora gratuita o con tarifas bajas, y se aplican mecanismos compensatorios, si bien hasta ahora se enmarcan dentro del ámbito nacional.

Se trata, sin duda, de un enfoque equitativo, pero que todavía se inscribe en una lógica propietarista y comercial. Con la Convención sobre la diversidad biológica, que entró en vigor en 1993, se reafirmaron los derechos soberanos de los Estados sobre sus recursos biológicos, y el Protocolo sobre el acceso y el reparto de las ventajas derivadas de la diversidad, adoptado en la Conferencia de Nagoya en octubre de 2010, se contenta con reglamentar el acceso de las empresas: petición oficial y autorización concedida por los países. No se ha tenido en cuenta la cuestión de la protección del saber tradicional, ni la del control de la explotación, ni las categorías de recursos protegidos (aparte de los genéticos), y la patente asimetría entre los Estados que controlan la tecnología y el resto sigue siendo dominante, lo que explica la oposición al Protocolo que ejercen los países en vías de desarrollo. Los "derechos de los pueblos autóctonos" fueron objeto de una Resolución de las Naciones Unidas el 13 de septiembre de 2007, que proclama su "derecho a preservar, controlar, repartir y desarrollar" su patrimonio y sus conocimientos tradicionales. No obstante, hay que ir más allá y reflexionar sobre la apropiación indispensable previa a la determinación de los modos de gestión.

\section{B) Los bienes públicos nacionales}

Ya se trate del dominio público o del privado, la gestión de los bienes de las personas públicas nos lleva a distinguir entre dos categorías de bienes: aquéllos cuya gestión debe contribuir a su protección y puesta en valor, por su interés ecológico, histórico o político, y aquéllos que tienen tendencia a ser gestionados desde la preocupación por la utilidad y rentabilidad económica de los mismos.

El problema radica en un primer momento en distinguir entre estas dos categorías de bienes, y luego de escoger las reglas más eficaces para responder a los dos objetivos distintos. Los legisladores han sido muy generosos al calificar de patrimonio común al conjunto de bienes medioambientales. Incluso han ido más lejos en lo que respecta a determinados recursos, declarando en 2006 que "el uso del agua pertenece a todos", teniendo todos derecho de acceso al agua potable "en condiciones económicamente aceptables", es decir, un acceso abierto a los más desfavorecidos.

No se puede negar que la gestión de los bienes demaniales, incluidos los bienes medioambientales, puede necesitar de un partenariado público-privado, con la diferencia de que en cuanto a los primeros la lógica de mercado debe permanecer discreta, mientras que, con respecto a los segundos, ésta se puede desarrollar con mayor libertad. En 1996 advertimos sobre los riesgos que la promoción de la valorización 24 económica del dominio público, aunque indispensable, podría engendrar para deter- 
minados bienes demaniales, principalmente los que integran el patrimonio cultural y natural (v. J. Morand-Deviller, "La valorisation économique du domaine public", en Mélanges R. Drago, Económica, 1996: "La crise du domaine public. A la recherche d'une Institution perdue", en Mélanges Jean-Francois Lachanme, Dalloz 2007). Esta cuestión es de actualidad ahora más que nunca. El fomento de la cesión de los bienes demaniales del Estado puede tener como consecuencia la privación de nuestro patrimonio arquitectónico de bienes de un valor artístico y "memorial” excepcional, una tentación de enriquecimiento a corto plazo, pero que a menudo resulta ser un mal negocio a medio y largo plazo, tal y como lo muestran varias cesiones recientes.

La celebración de un arrendamiento enfitéutico no es un remedio milagroso. Cuando se acuerda para una duración larga, el ocupante privado cuenta con libertad absoluta para cambiar la adscripción y el propietario público, una vez recupera el bien que posee, estará en la práctica vinculado a la adscripción o asignación comercial que el arrendador le hubiera dado. A este respecto, una controversia reciente puede servir de ejemplo, la de la licitación que se convocó en enero de 2011 para ceder en arrendamiento enfitéutico el Hotel de la Marine, situado en la plaza de la Concordia de París, construido por el arquitecto Gabriel entre 1758 y 1774 y, según un colectivo de eruditos, "uno de los grandes edificios de la representación nacional" a caballo entre el Antiguo régimen y la Revolución. Los 20.000 m se destinaban en su mayoría a un grupo financiero internacional interesado en un conjunto hotelero y comercial, en donde el lujo alcanzaba su máximo exponente. Las críticas fueron de lo más duras: “Francia no pierde su memoria, sino que la vende". Léon Duguit podría haber visto su sueño eterno perturbado por esta desviación de la "función social" de la propiedad. La reacción de los "indignados" puso fin al proyecto e hizo que se confíase la gestión a la entidad pública del Grand Louvre.

Cómo apreciar las sutiles técnicas de intercambio de valores medioambientales traducidas en unidades de valor económico, es decir, los mercados de intercambio de las cuotas de gas de efecto invernadero y, más recientemente, los mercados de unidades de biodiversidad. Estos ingeniosos sistemas, inventados en los Estados Unidos, contribuyen, sin duda alguna, a reducir las amenazas de contaminación y de destrucción y las críticas de los que los presentan como la compra por parte de las empresas ya sea de un derecho para contaminar, ya sea de un derecho para destruir, son injustificadas. Pero cabe constatar que este comportamiento de las empresas ecoresponsables tiene por principal objeto permitir el desarrollo de la empresa en una lógica de gestión y permanece indiferente a los objetivos de apropiación colectiva y de solidaridad en la gestión de recursos. Sin duda un avance con respecto a las prácticas desastrosas de no derecho. Pero aquí también hay que ir más lejos y plantearse la gestión de la demanda más que la de la oferta, y la igualdad y la solidaridad entre los hombres en el uso de los bienes más allá de un rendimiento fundado exclusivamente en las herramientas económicas.

La mayor parte de los países conocen esta desviación. Ofreceremos un último ejemplo de la recuperación por la lógica mercantil de la gestión de un patrimonio co- 
lectivo: el de la medicina tradicional china. Calificada de "feudal" y de "superstición" en los años 50, y habiendo recuperado su honor 30 años más tarde, es objeto ahora de una reglamentación estricta, con la buena intención de controlar el uso de sus productos y métodos por parte de la medicina oficial, lo que implica reservar la explotación y la distribución de este saber tradicional única y exclusivamente a las empresas que cuentan con los medios para obtener las certificaciones necesarias, privándolas de su especificidad. Hay quien considera que si la UNESCO reconociese la etiqueta de "patrimonio inmaterial" ayudaría a preservar su autenticidad.

Estas reflexiones pretenden incitar a los juristas de derecho público a aportar su contribución al debate sobre los bienes mundiales con respecto a los que todavía se muestran muy distantes. Si los filósofos aluden a una nueva ética de solidaridad y de reparto, si los politólogos prevén la escisión de las fronteras tradicionales y una democracia participativa basándose en nuevas entidades, los juristas también desempeñan un papel esencial para aplicar las herramientas adecuadas para hacer efectivos estos fines.

Alimentada por las preocupaciones medioambientales, la gestión y el uso de los bienes públicos nos hace volver a las causas primeras, antes de ocuparnos de las consecuencias y de los efectos. Una de las causas primeras del malestar actual es la confusión entre los bienes y los métodos de gestión sin pretender aislar aquéllos que merezcan un estatus particular.

Puede que el postmodernismo de los derechos subjetivos, del partenariado público-privado, de la regulación, del consensualismo y de la mano invisible del mercado sea conveniente para la gestión de los bienes públicos que, a semejanza de los bienes privados, apoyan las actividades económicas, pero no conviene a la gestión de los "bienes comunes". Se impone una reflexión sobre el concepto de "valor" y hay que buscar una sinergia entre los valores comerciales y no comerciales, entre la apropiación individual y el uso y disfrute común. También nos lleva a preguntarnos sobre las nuevas funciones de las autoridades públicas; el concepto de Estado "guardián" recobra fuerza y no hay más que leer a Platón para encontrar cuáles son las cualidades de los guardianes de la Cité, una Cité ahora mundializada. 